\title{
High-Resolution GPS Tracking of Lyle's Flying Fox Between Temples and Orchards in Central Thailand
}

\author{
NATALIE WEBER, ${ }^{1}$ Department of Migration and Immuno Ecology, Max Planck Institute for Ornithology, Am Obstberg 1,78315, Radolfzell, \\ Germany \\ PRATEEP DUENGKAE, Department of Forest Biology, Faculty of Forestry, Kasetsart University, Bangkok 10900, Thailand \\ JAKOB FAHR, Department of Migration and Immuno Ecology, Max Planck Institute for Ornithology, Am Obstberg 1, 78315 Radolfzell, and \\ University of Konstanz, Department of Biology, Konstanz 78457, Germany \\ DINA K. N. DECHMANN, Department of Migration and Immuno Ecology, Max Planck Institute for Ornithology, Am Obstberg 1, 78315 \\ Radolfzell, and University of Konstanz, Department of Biology, Konstanz 78457, Germany \\ PATCHARAKITI PHENGSAKUL, Department of Forest Biology, Faculty of Forestry, Kasetsart University, Bangkok 10900, Thailand \\ WACHIRAPON KHUMBUCHA, Department of Forest Biology, Faculty of Forestry, Kasetsart University, Bangkok 10900, Thailand \\ BORIPAT SIRIAROONRAT, ${ }^{2}$ Food and Agriculture Organization of the United Nations (FAO), Emergency Center for Transboundary Animal \\ Disease (ECTAD), Hanoi, Vietnam \\ SUPAPORN WACHARAPLUESADEE, Faculty of Medicine, Chulalongkorn University, Bangkok 10330, Thailand \\ PATTARAPOL MANEEORN, Department of National Parks, Wildlife and Plant Conservation, Ministry of Natural Resources and Environment, \\ Bangkok, Thailand \\ MARTIN WIKELSKI, Department of Migration and Immuno Ecology, Max Planck Institute for Ornithology, Am Obstberg 1, 78315 Radolfzell, \\ and University of Konstanz, Department of Biology, Konstanz 78457, Germany \\ SCOTT NEWMAN, Food and Agriculture Organization of the United Nations (FAO), Emergency Center for Transboundary Animal Disease \\ (ECTAD), Hanoi, Vietnam
}

\begin{abstract}
Hunting and loss of natural habitats increasingly threaten tropical biodiversity and ecosystems, particularly in Southeast Asia. Flying foxes often persist in anthropogenic areas where other wildlife has vanished, and where they play a significant ecological role in vegetation regeneration in disturbed habitats. Detailed knowledge on the foraging behavior of flying foxes is crucial for understanding how they survive in degraded habitats and for the management of human-wildlife conflicts. Thailand still harbors large colonies (several thousand individuals) of Lyle's flying fox (Pteropus lylei), a species ranked as Vulnerable on the International Union for Conservation of Nature (IUCN) Red List, at temples situated in agricultural landscapes. We used high-resolution global positioning system (GPS) loggers to study the movement and foraging behavior of this species at 2 temples in central Thailand during 2 seasons. We analyzed GPS and acceleration data of 19 tagged individuals, and assessed habitat use and diet. Foraging individuals commuted between day roosts and foraging areas each night, followed by small-scale movements in foraging areas, and showed high site fidelity during the study period. Maximum linear distances between day roosts and foraging areas varied greatly between individuals $(2.2-23.6 \mathrm{~km})$ but were similar between seasons. Tracked bats mostly foraged in farmland, plantations, and gardens, yet our data indicate that small mangrove remnants constitute important habitat components for Lyle's flying fox. We recorded a highly diverse diet of 34 food plant species, comprised of exotic crops and native plants as available. Our results suggest that conservation and landscape managers should preserve remaining native trees and natural vegetation in the study area as resources for Lyle's flying fox, at the same time reducing potential for conflicts between bats and humans on crops. They can further be used for public information campaigns integrating the potential of Lyle's flying fox as dispersers of useful plants and the human health risks through zoonotic diseases associated with hunting and consumption of this species. (c) 2015 The Wildlife Society.
\end{abstract}

KEY WORDS activity, agricultural lands, central Thailand, diet, flying fox, foraging, GPS loggers, mangroves, movement patterns, Pteropus lylei.

${ }^{1} E$ mail: natalieweber@gmx.de

${ }^{2}$ Present address: Conservation and Education, Zoological Park

Organization, Bangkok 10300, Thailand 
Anthropogenic influences are causing massive changes in many ecosystems worldwide, especially forested ones. We are only starting to investigate the consequences that these changes will have on individual species as well as the longterm health and stability of these ecosystems. Old World fruit bats (Chiroptera: Pteropodidae) constitute a particularly affected group of organisms. More than 289 plant species are known to depend on pollination and seed dispersal by Old World fruit bats, providing essential ecosystem services in different habitats of the Old World tropics (Start and Marshall 1976, Fujita and Tuttle 1991, Mickleburgh et al. 1992, Muscarella and Fleming 2007, Kunz et al. 2011). More than half of these plants are used by humans, accounting for $23 \%$ of products from human-used plants in the Old World tropics and thus being of great economic importance (Fujita and Tuttle 1991, Hodgkison et al. 2003). The genus Pteropus is the largest genus of Old World fruit bats and contains more than 50 species, with the majority of species occurring on oceanic islands and in (sub-) tropical Asia. The high mobility of these flying foxes, especially of the larger species, makes them particularly relevant pollinators and seed dispersers in degraded or fragmented landscapes (Corlett 2009). In general, their movement patterns are influenced by the spatio-temporal distribution of food and roosting resources (Nelson 1965, Eby 1991).

Despite their ecological importance and increased conservation attention, flying foxes are globally threatened by habitat loss and hunting (Fujita and Tuttle 1991, Mickleburgh et al. 1992, Corlett 1998). Species- and site-specific studies on foraging ecology in particular are rare (Banack 1998, Stier and Mildenstein 2005) but essential to understand the ecological role of flying foxes in their ecosystems. Most species of flying foxes are gregarious and roost in large colonies, yet roosting requirements and preferences, important for the understanding of population dynamics and the estimation of threats to the bats, are not well understood (Hahn et al. 2014).

In Southeast Asia, conditions for flying foxes are especially critical. The relative deforestation rate and associated wildlife habitat loss in Southeast Asia is the highest for all tropical regions (Sodhi et al. 2004). In Thailand, loss of natural forests exceeded 50\% within 3 decades (1961-1998; Waggener 2001). In this context, expansion of agricultural lands must dramatically influence resource quantity and quality for flying foxes in the formerly forested habitats, raising the question if they are able to cope with these changes. In addition, hunting pressure is exceptionally high (Corlett 2007, Epstein et al. 2009, Harrison et al. 2011, Scheffers et al. 2012). Like many flying foxes, Lyle's flying fox (Pteropus lylei) is valued as bushmeat, used in traditional medicine, and persecuted as an orchard pest. As with most congeners, it is easy to hunt because of its large body size and formation of conspicuous colonies in trees (Fujita and Tuttle 1991; Mickleburgh et al. 1992, 2009). Loss of natural habitats also increases contact zones of humans and flying foxes, boosting the potential for human-wildlife conflicts as well as spillover events of zoonotic diseases with implications on human health (Epstein et al. 2006, Wolfe et al. 2007,
Daszak et al. 2012, Wood et al. 2012). In particular, Lyle's flying fox has been identified as host of Nipah virus, a human and livestock pathogen (Olson et al. 2002; Reynes et al. 2005; Wacharapluesadee et al. 2005, 2010). Adverse effects of this finding on the perception of flying foxes by humans could exacerbate anthropogenic threats to Lyle's flying fox and other flying foxes, creating a demand for studies that address the ecological benefits they provide to avoid potentially severe consequences on local ecosystems.

To fill some of these knowledge gaps, we targeted Lyle's flying fox in Thailand where this species occurs in a region that is densely inhabited by humans. Lyle's flying fox is 1 of only 2 Pteropus species restricted to the mainland, and the only Pteropus species in mainland Asia (Mickleburgh et al. 1992). This might imply particular ecological traits, but foraging ecology of Lyle's flying fox and its diet remain undocumented. The known distribution of Lyle's flying fox is limited to few colonies of several 100-1,000 individuals in Thailand, Vietnam, Cambodia, and a small disjunct area in southern China (Bumrungsri et al. 2008). The species is ranked as Vulnerable on the International Union for Conservation of Nature (IUCN) Red List because of substantial population declines, and it is listed on Appendix II of the Convention on International Trade in Endangered Species of Wild Fauna and Flora (CITES; http://www.cites. org/eng/app/appendices.php, accessed 16 Apr 2014).

We employed high resolution global positioning system (GPS) telemetry to assess the ecological implications of Lyle's flying fox in an anthropogenic landscape, elucidating relations between nightly movements, activity patterns, resource use, and roosting behavior during 2 different seasons in Thailand. Understanding of these parameters is essential to develop conservation strategies as well as advance interdisciplinary research by assessing disease spillover risks based on flying fox ecology (de Jong et al. 2013). We anticipated that Lyle's flying fox is a central-place forager that returns to its respective day roost after foraging. Because natural vegetation was scarce in the study area, we predicted that the bats would have large foraging ranges of several kilometers to fulfill their requirements. We further expected to detect seasonal differences in the foraging behavior, based on spatio-temporal changes in resource availability. In addition to our assumption that Lyle's flying fox-like most of its congeners-feeds on a broad variety of plants, we aimed to investigate whether, and to what extent, it forages on exotic agricultural crops or native forest plants in a humanshaped environment, thereby evaluating the potential for seed dispersal or pollination. Based on our results, we assessed the ecological role of Lyle's flying fox for vegetation regeneration in an agricultural landscape and estimated impact on the local human population, ultimately providing information to mitigate conflicts between Lyle's flying fox and humans.

\section{STUDY AREA}

We captured most of the tracked bats from a colony roosting in the Wat Luang (WL) Buddhist temple ("Wat" in Thai; $\left.13^{\circ} 30^{\prime} 18.90^{\prime \prime} \mathrm{N}, 101^{\circ} 09^{\prime} 54.90^{\prime \prime} \mathrm{E}\right)$, Chonburi Province in the 
eastern part of Thailand Inner Gulf. The size of this colony fluctuated between approximately 8,300 and 12,700 individuals during a period from October 2005 to September 2006 (Wacharapluesadee et al. 2010). We caught additional bats from Wat Pho Bang Khla (WP; $13^{\circ} 43^{\prime} 20.30^{\prime \prime} \mathrm{N}$, $101^{\circ} 12^{\prime} 6.70^{\prime \prime} \mathrm{E}$ ), which is roughly $24 \mathrm{~km}$ north of WL in Chachoengsao Province. The WP colony comprised between approximately 7,000 and 18,800 individuals according to a recent count in 2010 (Hengjan 2011). The landscapes within a $20-\mathrm{km}$ radius of the colonies had a welldeveloped infrastructure and were characterized by an agricultural matrix, lacking noteworthy patches of natural vegetation. Land use included farming of rice and other crops, orchards and gardens, plantations, fallows, and various animal farms, including fish and shrimp. The climate in the area is tropical-monsoonal, with a dry season from November to March, followed by a hot inter-monsoonal period until May, and a wet season from May to October.

\section{METHODS}

We collected data during 2 seasons in 2012: during the hot inter-monsoonal period in April and early May, and during the early dry season in November and early December. We caught flying foxes at WL during 7 afternoons between 1600 and 1800 hours in both seasons (24-26 Apr, 9-11 Nov, 21 Nov). At WP, we captured bats for tracking from 0500 to 0630 and from 1700 to 1830 hours on 17 and 18 November. We employed locally produced fishing nets, which were erected between the upper ends of 2 5-7-m-long bamboo or metal poles to capture bats when leaving the colony. We kept captured individuals in soft cloth bags until processed. We briefly anesthetized all individuals selected for tracking with an isoflurane inhalation to reduce stress to the animal and facilitate handling. We recorded body mass (ing) and forearm length (in $\mathrm{mm}$ ) of all individuals, and determined sex and reproductive state. All techniques for capturing and handling of bats followed standard methods (Sikes et al. 2011). In parallel, national disease researchers collected anal swabs and blood samples to test for Nipah virus. Permits to capture bats were issued by the Department of National Parks, Wildlife and Plant Conservation in Thailand (DNP 0909.204/2686).

We deployed 32 GPS loggers (e-obs $\mathrm{GmbH}$, Grünwald, Germany) on 30 adult males (WL Apr: 10, WL Nov: 10, WP: 10) and 2 adult females (WL Nov: 1, WP: 1). In April, most females were carrying young and thus we did not consider them for tracking to prevent extra load, stress, or abandonment of the young. The 2 females tracked in November were post-lactating. Mass of the GPS loggers used at WL (LiPo III) was $20.5 \mathrm{~g}$ and constituted 3.1-4.4\% of the body mass (mean body mass $\pm \mathrm{SD}: 539.7 \pm 55.8 \mathrm{~g}$, $n=21$ ), well below the $5 \%$ recommended for tracking devices of flying vertebrates (Aldridge and Brigham 1988). At WP, we used GPS loggers fitted with different batteries (Primary III) with a mass of $25.5 \mathrm{~g}$, accounting for $4.3-6.1 \%$ of the body mass (mean body mass $\pm \mathrm{SD}: 533.6 \pm 60.5 \mathrm{~g}$, $n=11$ ). This slightly exceeded $5 \%$ of the body mass in 2 tracked bats but remained below $10 \%$, which is considered as maximum threshold in bats weighing more than $70 \mathrm{~g}$ in several studies (O'Mara et al. 2014). We glued most loggers $(n=23)$ between the scapulae with skin adhesive (Manfred Sauer GmbH, Lobbach, Germany) after trimming the dorsal fur, followed by a second layer of instant glue. Previous studies with other bat species have shown that this attachment method causes no injuries to the animals, and that loggers fall off within a period of 2 weeks. The last batch of loggers $(n=9)$ was first superglued and then sewed on to T-shaped pieces of leather. We then tied these leather collars around the bats' neck with surgical thread (Safil C, B. Braun Petzold GmbH, Melsungen, Germany) that decomposes after about 1 month (O'Mara et al. 2014). All bats were hand fed with mangoes or bananas at the end of the handling procedure and subsequently released. We assigned bat identifications (IDs) that corresponded to the serial number of the logger attached.

\section{GPS Loggers}

The loggers were flexibly programmable to record GPS locations, 3-axial acceleration data, as well as flight speed and height. We obtained this information through remote download with a base station (Basestation b5, e-obs $\mathrm{GmbH}$, Grünwald, Germany), which connected to the loggers with an ultra high frequency (UHF) radio link as soon as the base station was within reading distance of the logger (i.e., within a radius of 100-200 m). In addition, the loggers produced radio signals (i.e., pinger) 2 hours each day to allow localization of the bats with a radio receiver (AOR AR8200, AOR LTD., Tokyo, Japan) if they were outside the range of the base station. Both base station and radio receiver were connected with a 10-element Yagi-antenna (eobs, Munich, Germany). Specifically, we applied the following settings: GPS on from 1759 to 0601 hours local time, pinger on from 1000 to 1200 hours, acceleration data collection $15 \mathrm{~s} / \mathrm{min}$ at a byte count of $1,188(56.23 \mathrm{~Hz})$ on 3 axes during the entire runtime of the loggers, base station radio interval for data download of 20 seconds, and data collection stopped when battery voltage below $2.785 \mathrm{~V}$ (LiPo III) or $2.458 \mathrm{~V}$ (Primary III) to retain sufficient battery capacity for data download. We collected GPS fixes every 1,800 seconds when bats were stationary. As soon as bats started flying, the interval switched to 150 seconds. For more detailed information on the logger programming, please contact the authors or e-obs.

Corresponding to the pinger settings, we walked through the bat colonies every day between 1000 and 1200 hours for data download, scanning through the frequencies and approaching located loggers. The base station was operating simultaneously. When it established connection to a logger, data download started automatically. We transferred successfully downloaded data with a secure digital (SD) memory card from the base station to a notebook computer. We restricted all subsequent analyses to loggers from which at least 2 24-hour cycles of data were downloaded. In addition, we did not analyze data from the first night following logger attachment if not otherwise mentioned, to minimize potential effects of handling on the behavior of the 
bats. We performed all $t$-tests and Mann-Whitney $U$-tests for statistical comparison of data samples with SIGMASTAT Version 3.5 (Systat Software, San Jose, CA).

\section{Spatial Data}

We extracted GPS points with the decoder software provided by the logger manufacturers, and plotted them in Google Earth (Version 7.1). We also transferred all data to Movebank (www.movebank.org; Wikelski and Kays 2010), a global repository of animal movement data, where they are publicly visible. We used ArcView GIS 3.2a (ESRI, Redlands, CA) in Universal Transverse Mercator (UTM) coordinates (UTM zone 47N) to calculate cumulative distances flown per night and individual by connecting all GPS points from complete nights starting at 1800 until 0600 hours with straight lines. In addition, we measured maximum foraging distances for each individual from its colony to the most distant GPS point.

Based on the spatial context, we assigned GPS points to 3 categories: roost (all points in immediate vicinity of the colonies), commute (all points connecting a colony and a foraging area, or discrete foraging areas), and foraging (all points other than the day roosts where bats spent time at night but were not commuting). This classification was later visually checked for consistency and refined with acceleration data, whereby roost and forage included all behavioral categories described below, and commute was restricted to flight activity.

\section{Acceleration Data}

The acceleration sensor output reflects changes in the orientation of the logger as well as accelerated translational movements. We plotted acceleration data with the Movebank acceleration viewer tool (https:/www.3dyne.com/ movebank-acceleration-viewer, accessed 17 Nov 2013; Holland et al. 2009) that visualizes deflections of the device on 3 perpendicular axes. We assigned fruit bat behavior to 7 categories based on certain patterns in the acceleration data (see Fig. S1, available online at www.onlinelibrary.wiley. com): resting (sleeping or otherwise non-moving), moving (active but not flying), flying (15-second burst completely composed of flying activity, i.e., commuting between roosts and food trees or between food trees), fanning (continuous wing flapping in otherwise resting position), starting (flight activity set in during the 15 -second burst), landing (flight activity stopped during the 15 -second burst), and short flight (flight activity started and ended during the 15-second burst). We cross-checked classification of acceleration data with GPS points in Google Earth. We exported categorized acceleration data to Excel for further analyses.

To check for seasonal differences in activity patterns, we used only acceleration data of bats from WL, which were exposed to the same environment, for consistent data sets. Further, we restricted analyses to data of the second night and day after logger attachment, resulting in 24 hours of acceleration information for each individual $(n=16)$. Acceleration data of subsequent nights did not show significant differences in 3 randomly chosen individuals. We defined beginning of night at 1800 hours local time, beginning of day at 0600 hours local time. We calculated the percentage of each behavioral category in the overall activity budget per night and day, as well as percentages of acceleration categories within certain GPS point categories at night.

\section{Habitats and Diet}

We visited most sites used by the bats at night for groundtruthing based on GPS points (27 Apr-8 May, 12 Nov-4 Dec 2012). We used a hand-held GPS receiver (Garmin GPSmap 62s, Garmin, Olathe, KS) to home in on the foraging individuals. The high data accuracy of the loggers allowed identification of feeding and roosting (groups of) trees of each bat. We noted the habitat type at each locality. We recorded information on feeding remains below trees, such as chewed pieces of fruits and/or bat droppings, if available and used this information to verify the actual use as a food tree and/or feeding roost. We identified all relevant trees, most of them to species level. To test for seasonal differences in food plant species composition of bats from WL, we computed a matrix of pairwise Sørensen distances based on presence-absence of food plants in the diet of each individual using PC-ORD 5 (MjM Software Design, Gleneden Beach, OR). We subsequently grouped distance values into inter- and intraseasonal pairings, for statistical comparison of dietary dissimilarity within and between seasons.

\section{RESULTS}

We downloaded data from 24 of the 32 GPS loggers. We excluded 5 of the 24 loggers from further analyses because the retrieved data did not cover a minimum of 224 -hour cycles. The 8 loggers without downloaded data were most likely on bats that did not return to WL or WP within the battery lifetime of the logger for unknown reasons, or on bats that removed the logger while away from the colony. Data of the remaining 19 loggers resulted in 97 tracking nights and 6,076 GPS bearings (Table 1). On average, we collected data for $5.1 \pm 1.6$ nights per bat (range: LiPo III 3-8 nights, Primary III 5-10 nights). Mean number of GPS points per individual was $320 \pm 124$ (range: 182-705; Table 1). We obtained 11,347 acceleration bursts on the second night and 11,492 acceleration bursts on the second day after logger attachment from tracked bats from WL for both seasons.

\section{Movement Patterns and Flight Distances}

Movements of the tracked bats in the study area were characterized by commuting flights between day roosts and foraging areas, or between different foraging areas, and small-scale movements within the foraging areas (Fig. 1). Site fidelity to foraging areas was high for most individuals during the tracking period; the majority of tracked bats $(n=13)$ almost exclusively exploited the same foraging areas every night, up to a maximum of 10 nights (bat 2277; Table 1). The other individuals $(n=6)$ also repeatedly frequented the same localities but either included additional areas or shifted some localities during the tracking period.

The maximum linear distances from day roosts to foraging areas varied considerably between individuals $(2.2-23.6 \mathrm{~km}$; 
Table 1. Number of tracking nights and global positioning system (GPS) points, maximum linear distances (all distances in km) between colonies in Wat Luang (WL) and Wat Pho Bang Khla (WP) and foraging areas (max. dist.), cumulative distances during the second tracking night (cum dist n2), and mean cumulative distances (cum dist $\bar{x}$ ), with mean and standard deviation (SD) values, of 16 tracked males of Lyle's flying foxes at WL and 3 tracked males of Lyle's flying foxes at WP, Thailand, in 2012.

\begin{tabular}{|c|c|c|c|c|c|c|c|}
\hline Locality & Season & Bat ID & No. nights & No. GPS points & Max.dist & Cum dist n2 & Cum dist $\bar{x}$ \\
\hline \multirow[t]{10}{*}{ WL } & Apr May & 2268 & 4 & 259 & 3.8 & 11.6 & 13.6 \\
\hline & & 2272 & 4 & 228 & 5.2 & 14.8 & 14.6 \\
\hline & & 2274 & 8 & 392 & 7.1 & 13.3 & 16.7 \\
\hline & & 2286 & 5 & 268 & 8.7 & 30.8 & 25.1 \\
\hline & & 2289 & 5 & 319 & 5.5 & 17.4 & 16.0 \\
\hline & & 2292 & 5 & 249 & 12.7 & 28.6 & 21.7 \\
\hline & & 2296 & 5 & 312 & 17.1 & 14.1 & 24.6 \\
\hline & & 2299 & 5 & 312 & 18.5 & 38.0 & 39.1 \\
\hline & & $\bar{x}$ & 5.1 & 287.8 & 10.5 & 19.3 & \\
\hline & & $\mathrm{SD}$ & 1.2 & 50.8 & 5.7 & 10.8 & \\
\hline \multirow[t]{8}{*}{ WL } & Nov & 2269 & 3 & 185 & 9.2 & 20.2 & 20.7 \\
\hline & & 2270 & 5 & 253 & 9.7 & 25.2 & 22.9 \\
\hline & & 2273 & 4 & 311 & 22.3 & 43.8 & 44.5 \\
\hline & & 2287 & 3 & 182 & 17.1 & 31.8 & 31.8 \\
\hline & & 2290 & 6 & 521 & 19.0 & 42.7 & 41.4 \\
\hline & & 2295 & 6 & 424 & 2.2 & 8.9 & 8.3 \\
\hline & & $\bar{x}$ & 4.7 & 305.7 & 13.5 & 28.4 & \\
\hline & & $\mathrm{SD}$ & 1.3 & 125.7 & 6.9 & 12.3 & \\
\hline \multirow[t]{5}{*}{ WP } & Nov & 2276 & 5 & 343 & 7.2 & 29.4 & 16.7 \\
\hline & & 2277 & 10 & 705 & 4.0 & 11.2 & 10.0 \\
\hline & & 2284 & 5 & 298 & 23.6 & 49.2 & 49.5 \\
\hline & & $\bar{x}$ & 6.3 & 448.7 & 11.6 & 29.9 & \\
\hline & & $\mathrm{SD}$ & 2.5 & 223.1 & 10.5 & 19.0 & \\
\hline Total & & & 97 & 6,076 & & & \\
\hline $\bar{x}$ & & & 5.1 & 319.8 & 11.8 & 24.3 & \\
\hline SD & & & 1.6 & 123.7 & 6.6 & 12.9 & \\
\hline
\end{tabular}

Table 1). Mean maximum distances recorded at WL during November $(13.5 \mathrm{~km})$ were longer than during April $(10.5 \mathrm{~km})$, but this was not statistically significant $(t=0.96, \quad P=0.356)$. Both mean cumulative nightly distances per individual, and cumulative distances of second tracking nights, also varied considerably among individuals (mean: 8.3-49.5 km; second night: 4.8-49.2 km; Table 1). As with maximum linear distances, mean values for cumulative distances recorded in November exceeded values in April (Table 1) but did not differ statistically (mean: $t=1.39$, $P=0.185$; second night: $t=1.57, P=0.137$ ).

\section{Activity Patterns}

There were no seasonal differences between nightly activity budgets of the tracked bats based on behavioral categories from acceleration data. The time used for commuting as determined with GPS and acceleration data was not significantly higher in November $(8.0 \pm 3.9 \%$; Table 2) than April $(4.9 \pm 3.4 \%)$. However, bats spent significantly more time at foraging areas and less at the day roost in November compared to April (Table 2). Activity budgets during the time spent in foraging areas were similar in both seasons. During the day, only the categories fanning (higher in Apr) and moving (higher in Nov) showed significant seasonal differences (Table 2).

\section{Habitat Use and Diet}

Habitat use of tracked Lyle's flying foxes of both colonies reflected the agricultural landscape of the study area, and the lack of natural habitats. All 19 individuals foraged almost exclusively in orchards, plantations, mixed tree rows planted as living fences between fish or shrimp ponds, farm yards, fallows, and tree stands alongside roads. More than half $(52.6 \% ; n=10)$ of the tracked individuals visited temples other than WL and WP for feeding and roosting at night. Almost a quarter $(21.1 \% ; n=4)$ of the bats occasionally foraged in small patches of mangrove remnants along rivers. Given the anthropogenic character of the study area, the number of potential contact zones and encounters between bats and humans as well as domestic animals was high.

Based on the tracking data of 1 individual from WL in November (bat 2287), which did not return to the temple colony for some days, we discovered an additional day roost of Lyle's flying fox $\left(13^{\circ} 35^{\prime} 21.26^{\prime \prime} \mathrm{N}, 101^{\circ} 02^{\prime} 01.63^{\prime \prime} \mathrm{E}\right)$. This colony was located in a narrow strip of mangrove trees in a swamp area along the Bang Pakong River, $17 \mathrm{~km}$ northwest of WL and $23 \mathrm{~km}$ southwest of WP. It comprised approximately 1,000-2,000 individuals at the time of visit, and bats used Avicennia alba as roosting trees.

Assessment of diet included data of all tracking nights of the 19 bats, including the first night after logger attachment. The bats used 34 plant species as food, predominantly fruits (Table 3). Consumption of leaves and flowers is generally difficult to detect with ground-truthing because feeding signs are barely traceable, but we included 3 non-fruiting plant species (Acacia auriculiformis, Eucalyptus sp., Markbamia stipulata) on the list because GPS data provided high evidence for their use. 

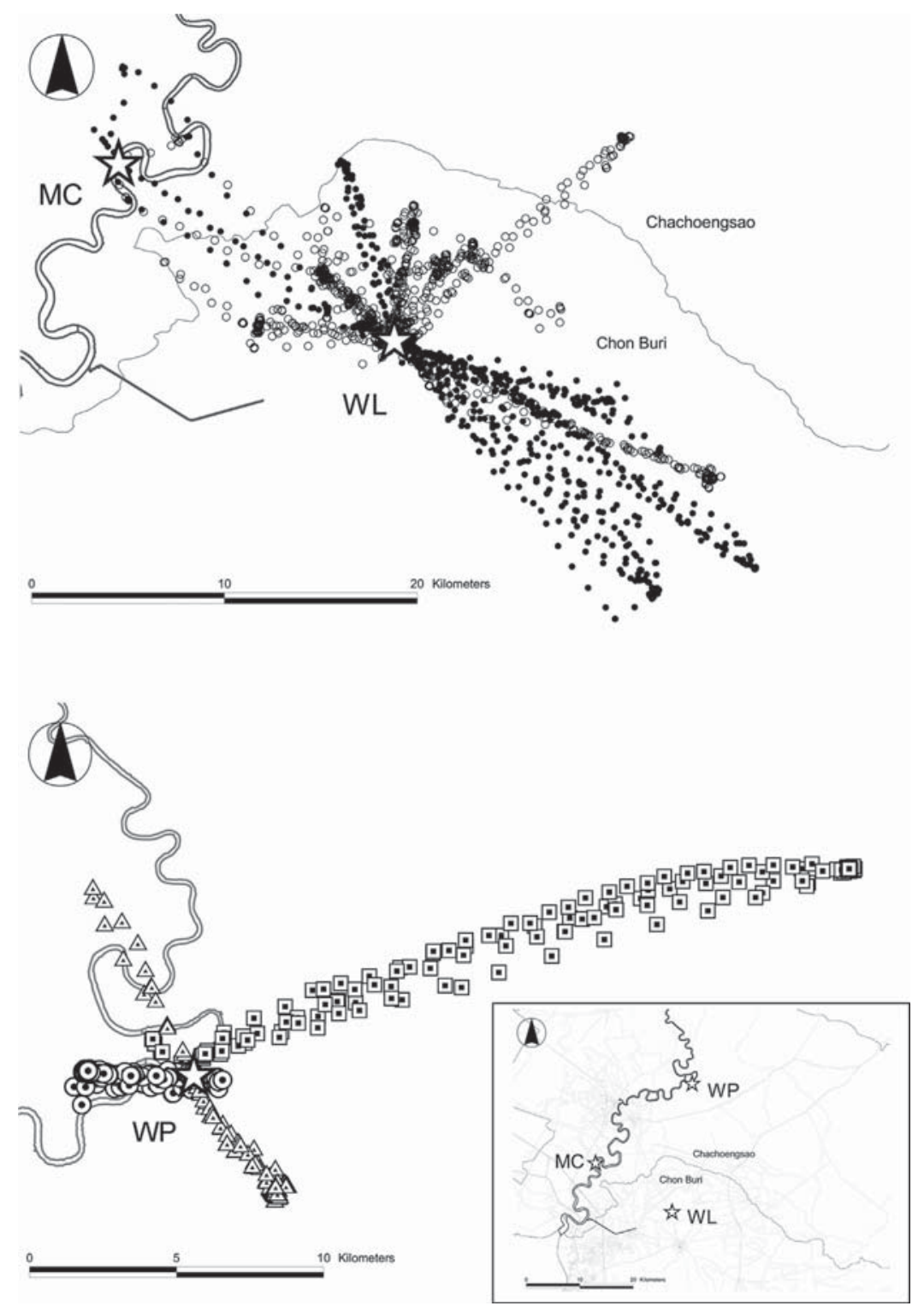

Figure 1. Global positioning system (GPS) tracks of 19 Lyle's flying foxes in Wat Luang (WL) and Wat Pho Bang Khla (WP), Thailand, 2012 (stars: colonies, MC: mangrove colony). Above: WL and MC (empty circles: Apr May, solid circles: Nov). Below: WP (triangles: bat 2276, squares: bat 2284, circles: bat 2277). Bang Pakong River plotted as dark grey doublet in all maps.

Overall, mango (Mangifera indica) was the most frequently eaten fruit, which was consumed by 10 bats. Bananas (Musa sp.) ranked second ( $n=7$ bats), and tamarind (Tamarindus indica) third ( $n=6$ bats). Figs (Ficus spp.) represented the most common genus with the highest percentage in the total number of food plant species $(20.6 \%$, $n=7)$. Almost half of the 34 food plant species $(47.1 \%$, $n=16$ ) were each consumed by only 1 individual. For both study periods, the list of food plants comprised various native species such as Chinese fig (Ficus microcarpa), monkey jack (Artocarpus lakoocha), ivy gourd (Coccinia grandis), and gaub tree (Diospyros malabarica) as well as introduced trees, for example strawberry tree (Muntingia calabura), papaya (Carica papaya), and cashew (Anacardium occidentale). All of the fruits consumed by the bats are considered useful for humans to some degree, and many of them are likely dispersed by the bats. Some fruits are of high economic value such as mango and cashew. Others, such as the native fig trees, are appreciated for their shade. The mangrove apple (Sonneratia caseolaris) constitutes the only species that does not grow on agricultural land, and it was restricted to the only mangroves in the study area along the Bang Pakong River.

Diet of the bats varied between seasons. The overall number of food plant species recorded during November $(n=27)$ was considerably higher than during April $(n=17)$. In addition, we recorded more food plant species exclusively in November $(n=17)$ than in April $(n=7)$. Composition of food plant species was less similar between individuals during different seasons than within seasons (Mann-Whitney $U$ test: $T=2,903, P=0.002$; Fig. 2). Tracked bats tended to use a higher number of food plant species per individual in 


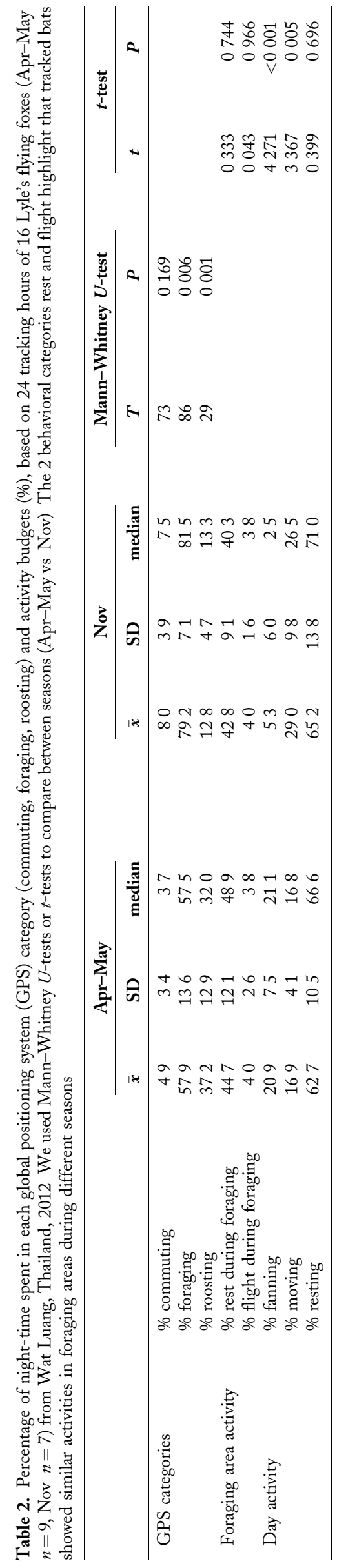

November (mean: $5.7 \pm 2.8$ ) than in April (mean: $3.6 \pm 1.3$; $t=2.071, P=0.054)$.

\section{DISCUSSION}

The results of this first study on the foraging ecology of Lyle's flying fox showed that individuals used the agricultural landscapes within a roughly $20-\mathrm{km}$ radius around their day roosts. Neither movement patterns nor activity budgets exhibited significant seasonal differences except for the length of nightly foraging activity. Tracked bats foraged on a diverse diet of agricultural crops and native forest plants with seasonal changes in composition. Our results revealed that Lyle's flying fox is able to persist in a landscape profoundly shaped by human land use, which is possibly because of the availability of safe day roost sites and sufficient food resources.

Deployment of advanced GPS loggers allowed us to collect spatial and temporal data at a high resolution, which is not possible with the more commonly used satellite transmitters. The latter are highly valuable for observations of long distance movements of flying foxes (Epstein et al. 2009, Breed et al. 2010), but high inaccuracy and low frequency of location fixes limit their use for studies of fine-grained movements. Our GPS loggers were battery-powered and had rather limited life spans because the mass of the batteries was constrained by the total weight the animals could carry. However, to obtain insights into seasonal variability, we spaced data collection as to cover 2 climatically distinct seasons, while we recognize that the foraging behavior of Lyle's flying fox might be different at other times of the year.

During consecutive tracking nights, most of the bats from both temples showed high site fidelity to foraging areas. This behavior was not surprising because bats save time and energy by returning to predictable food resources that are available for a certain period (von Helversen and Winter 2003). Some individuals shifted foraging areas during the tracking time, and in some cases we observed that the previously visited trees had stopped or reduced fruiting. This reflected that bats turned to other food sources when a source got depleted over time and/or through food competitors. Tracked bats sporadically also visited additional localities, probably either to scout for upcoming food resources, or to get supplementary food items required to complement their diet (e.g., plants exclusively found in mangrove habitats).

Both overall nightly activity budgets and relative activity budgets in foraging areas were similar during different tracking seasons, although tracked Lyle's flying foxes spent a higher proportion of time in foraging areas in November compared to April. Given that the proportion of resting time was nearly equal between seasons for both night and day, our data suggest that the bats required stable amounts of resting time to maintain their energy balance. This feature was particularly marked during the day, when fanning activity increased significantly during the hot season, facilitating thermoregulation (Ochoa-Acun and Kunz 1999, Markus and Blackshaw 2002). A higher proportion of time spent fanning was accompanied by a reduction of moving activity 
Table 3. Food plant species of 19 individuals of Lyle's flying fox at Wat Luang (WL) and Wat Pho Bang Khla (WP), Thailand, 2012 (X: direct evidence from feces or feeding remains; $\mathrm{O}$ : information based on evidence from location data but with no direct evidence from feces or feeding remains). If not otherwise mentioned, the plants were visited by Lyle's flying fox for their fruits (Fl: flower, L: leaves).

\begin{tabular}{|c|c|c|c|}
\hline \multirow[b]{2}{*}{ Species } & \multicolumn{2}{|c|}{ WL } & \multirow{2}{*}{$\frac{\text { WP }}{\text { Nov }}$} \\
\hline & Apr May & Nov & \\
\hline Acacia auriculiformis (earleaf acacia) & & $\mathrm{X}(\mathrm{Fl} / \mathrm{L})$ & $\mathrm{X}(\mathrm{Fl} / \mathrm{L})$ \\
\hline Artocarpus lakoocha (monkey jack) & & $\mathrm{X}$ & $X$ \\
\hline Carica papaya (papaya) & & $\mathrm{X}$ & $X$ \\
\hline Coccinia grandis (ivy gourd) & & $\mathrm{X}$ & $\mathrm{X}$ \\
\hline Diospyros malabarica (gaub tree) & $\mathrm{X}$ & & \\
\hline Diospyros rhodocalyx & & $\mathrm{X}$ & \\
\hline Eucalyptus sp. (eucalyptus) & $\mathrm{O}(\mathrm{Fl} / \mathrm{L})$ & $\mathrm{O}(\mathrm{Fl} / \mathrm{L})$ & \\
\hline Ficus benjamina (weeping fig) & & X & \\
\hline Ficus concinna & & $\mathrm{X}$ & \\
\hline Ficus glaberrima & & & $\mathrm{X}$ \\
\hline Ficus microcarpa (Chinese fig) & $\mathrm{X}$ & $\mathrm{X}$ & $\mathrm{X}$ \\
\hline Ficus religiosa (sacred fig) & & $\mathrm{X}$ & $\mathrm{X}$ \\
\hline Ficus rubiginosa (rusty leaf fig) & $\mathrm{X}$ & $\mathrm{X}$ & \\
\hline Mangifera indica (mango) & $\mathrm{X}$ & $\mathrm{X}$ & $\mathrm{X}$ \\
\hline Manilkara zapota (sapodilla) & & $\mathrm{X}$ & \\
\hline Markhamia stipulata & & $\mathrm{O}(\mathrm{Fl} / \mathrm{L})$ & \\
\hline Microcos tomentosa & & $\mathrm{O}$ & \\
\hline Mimusops elengi (Spanish cherry) & & $\mathrm{X}$ & \\
\hline Morinda citrifolia (Indian mulberry) & $\mathrm{X}$ & $\mathrm{X}$ & \\
\hline Muntingia calabura (strawberry tree) & $\mathrm{X}$ & $\mathrm{X}$ & \\
\hline Musa sp. (banana) & $\mathrm{O}$ & $\mathrm{X}$ & $\mathrm{X}$ \\
\hline Passiflora foetida (wild maracuja) & $\mathrm{O}$ & & \\
\hline Pithecellobium dulce (Manila tamarind) & $\mathrm{O}$ & & \\
\hline Psidium guajava (common guava) & $\mathrm{O}$ & $X$ & $\mathrm{X}$ \\
\hline Sandoricum koetjape (santol) & $\mathrm{O}$ & & \\
\hline Sonneratia caseolaris (mangrove apple) & $\mathrm{X}$ & & \\
\hline Syzygium cumini (black plum) & $\mathrm{X}$ & & \\
\hline Syzygium jambos (Malabar plum) & & $\mathrm{X}$ & \\
\hline Syzygium samarangense (Java Apple) & $\mathrm{X}$ & $\mathrm{X}$ & \\
\hline
\end{tabular}

and vice versa, obviously offsetting each other, without effects on the proportion of time spent resting.

Identification of 34 food plant species revealed that Lyle's flying fox fed on a broad variety of plants, most of which are also used by humans. The majority of food plants was visited for fruits. Most of the fruits consumed by Lyle's flying fox in this study are also known to be used by other flying foxes in the Asia-Pacific region, notably mangos and other commercial fruits such as cashew and tamarind (Stier and Mildenstein 2005, Luskin 2009, Vendan and Kaleeswaran 2011), as well as different fig species (Stier and Mildenstein 2005, Luskin 2009, Sudhakaran and Doss 2012, Prasad et al. 2014). Fruits in the genus Artocarpus and Syzygium are also repeatedly documented in the diet of flying foxes (Banack 1998, Nelson et al. 2000a, Stier and Mildenstein 2005, Luskin 2009). Our study may represent a reasonable approximation of the diet of Lyle's flying fox during 2 seasonal extremes within the study landscapes. Assessment of the diet of Lyle's flying fox in different habitats throughout its range, however, would likely yield a different list of food plant species. Further studies in different habitats are thus required to comprehend the influences of habitat condition on the diet and foraging ecology of Lyle's flying fox, and its potential as a seed disperser and pollinator.
Composition of food plant species of individual flying foxes varied between seasons, with a high number of food resources exclusively used during 1 study period. Seasonal differences in diet as a consequence of changes in food availability are known from other flying foxes in the Asia-Pacific region (Banack 1998, Stier and Mildenstein 2005, Mahmood-ulHassan et al. 2010). While seasonal patterns in fruiting and flowering are likely in native trees such as the gaub tree, monkey jack, and mangrove apple, the 3 most frequently used food plant species, the cultivated crops mango, banana, and tamarind, were consumed by bats during both study periods. The stable supply of agricultural crops likely reduced seasonal shifts and potential bottlenecks of food resources in the diet of Lyle's flying fox, and seasonal differences might be more pronounced if bats used only natural food plants with a limited temporal availability. The number of food plant species, both combined and on an individual level, also varied between seasons, with a greater number of plants used in November than in April. It is tempting to relate this observation to the peak production of mango during the latter season, when plenty of mango plantations constituted a major and predictable resource for Lyle's flying fox. Although commercial production of mangos is frequently extended with chemical agents in Thailand throughout the 


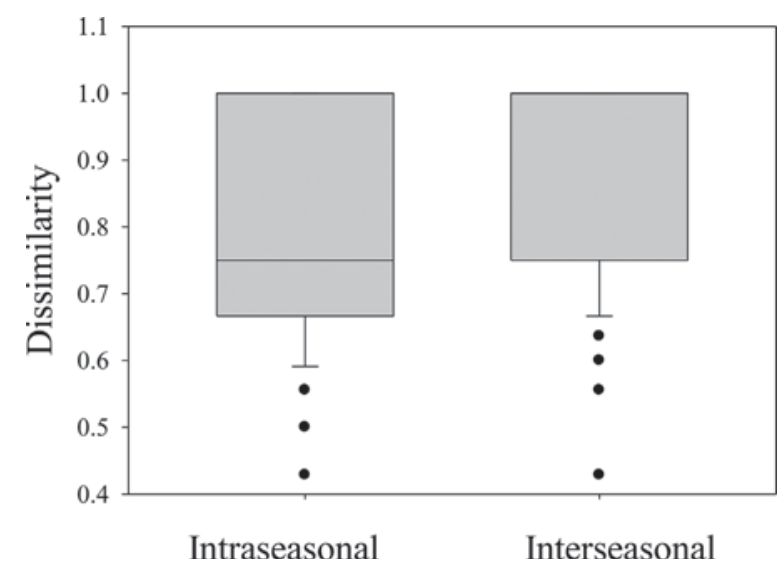

Figure 2. Box plots of intra and inter seasonal differences in diet (Sørensen distances) between 16 individuals of Lyle's flying fox from Wat Luang, Thailand, 2012. Dots represent outliers. For the interseasonal box plot, both the median (line) and the third quartile (upper box extent) have the value 1 .

year (Nartvaranant et al. 2000, Benjawan et al. 2006), fruiting of mango trees was clearly reduced in November. The number of available fruit species might have increased shortly after the wet season in November.

Out of the 31 plant species used as fruit resources by the bats, at least $42 \%$ were cash crops, and at least 39\% were native forest plants. Regarding the fruits intensively used by humans, competition for these resources between bats and humans has substantial potential for a conflict of interest. However, bats are probably contributing to seed dispersal and natural regeneration of some of the cash crops (see also Bumrungsri et al. 2013). In addition, flying foxes preferentially consume ripe fruits that would no longer be useful for commercial purposes (Banack 1998, Nelson et al. 2000b). Our data also indicate that Lyle's flying fox used native food plants when they were available, in line with previous studies demonstrating that flying foxes use orchard plants after natural forest food plants have become rare (P. samoensis, Nelson et al. 2000a, P. vampyrus, Mohd-Azlan et al. 2001). Foraging areas of Lyle's flying fox were almost exclusively situated in agricultural lands because cultivation and inherent loss of natural forest habitats have shaped the study area. Agricultural crops were seemingly beneficial for Lyle's flying fox, and might have increased food availability for flying foxes compared to forest habitats where food resources would be expected to have a lower density in an equal-sized area.

Lyle's flying foxes, however, also visited small remaining patches of mangroves and scattered individuals of native trees, and these foraging bouts could have important implications for the regeneration of these vegetation patches (Shanahan et al. 2001, Hodgkison et al. 2003). Flying foxes are particularly effective when dispersing small seeds that are swallowed, such as those of figs, over long distances in fragmented and degraded landscapes such as our study area (Shilton et al. 1999, Corlett 2009, Sritongchuay et al. 2014). Larger seeds are also frequently carried away from the fruiting tree to a feeding roost, and we observed dispersal distances of $300 \mathrm{~m}$ for seeds of the gaub tree, surpassing reported regular distances of $200 \mathrm{~m}$ (Corlett 2009). The importance of flying foxes for seed dispersal of native tree species as well as their potential for wasteland regeneration and nutrient cycling (Luskin 2010) might outweigh any economic damage caused by Lyle's flying fox in the study area. Lyle's flying fox is also likely to play essential roles in mangrove regeneration in the study area. Pteropodids are generally recognized to be indispensable for pollination and seed dispersal of the mangrove apple (van der Pijl 1982, Watzke 2006). Mangrove habitats are increasingly rare in Thailand and threatened by agricultural expansion, mostly through shrimp farming (Hazarika et al. 2000, Barbier 2003). In the study area, only small pockets along the Bang Pakong river remain.

The high number of native fig species $(n=6)$ in the diet of tracked bats underlines the relevance of native vegetation in the study area for Lyle's flying fox. Figs probably constituted food resources with a high nutritional value for the bats because they are rich in nutrients such as calcium and protein compared to cultivated fruits (Nelson et al. 2000a). Previous studies have already highlighted the importance of figs as keystone species for flying foxes (Fujita and Tuttle 1991, Nelson et al. 2000a, Shanahan et al. 2001), potentially even limiting their occurrence (Stier and Mildenstein 2005). Consequently, preservation of fig trees is likely vital to fulfill nutritional requirements of the local colonies of Lyle's flying fox.

Alongside foraging habitats, suitable roost sites are a major factor determining the occurrence and movements of flying foxes. The 2 main day roosts in the study area, WL and WP, harbored the majority of Lyle's flying foxes throughout our study, contrasting the behavior of other Pteropus species that commonly show nomadism and only seasonal roost fidelity in relation to spatio-temporal changes in food availability (Nelson 1965, Tidemann et al. 1999, Banack and Grant 2002, Gumal 2004, Roberts et al. 2012). In an urbanized area of Australia, however, year-round food availability probably led to increasing residency and loss of migratory behavior in grey-headed flying foxes ( $P$. poliocephalus; McDonaldMadden et al. 2005). The stable supply with mixed food resources observed in our study may have also fostered residency of bats, although this assumption is limited given that no data about migration in Lyle's flying fox is available. In addition, both temples are traditional roosting sites providing suitable roost trees (Hahn et al. 2014) where bats are safe from hunting (Hillman 2005). Persistence of the roost site in the mangrove patch, which is accessible to people because of its small size and thus exposes the bats to hunters (Mohd-Azlan et al. 2001), testifies to the significance of mangroves as roosting habitat for Lyle's flying fox (Pierson and Rainey 1992).

According to local farmers, Lyle's flying fox is hunted as an orchard pest in the study area. Awareness among people of the likely contribution to the dispersal of both ecologically and economically valuable plants by flying foxes appeared to be scarce. To sustain the services provided by the bats, it is crucial to maintain local colony sizes of Lyle's flying fox above a certain threshold value below which their ecological 
functionality and effectiveness as seed disperser is expected to be compromised (McConkey and Drake 2006). Finally, our interviews revealed that Lyle's flying fox is hunted in the study area for bushmeat and traditional medicine. Bats are highly valued as an ingredient of curries, and fresh blood is considered a powerful energy drink. The latter practice might not only result in depletion of local colonies of Lyle's flying fox but also have serious implications for human health as consumption of fresh blood is very likely to facilitate transmission of the Nipah virus (Wacharapluesadee et al. 2006) and other human pathogens (see also Epstein et al. 2006). Elimination of hunting would thus reduce the risk of disease transmission and at the same time aid to safeguard the ecological benefits provided by the bats.

\section{MANAGEMENT IMPLICATIONS}

The continuous existence of large colonies of Lyle's flying fox in the agricultural landscape of the study area points to a highly flexible foraging behavior in this species. We expect the foraging behavior of Lyle's flying fox to be different in another habitat setting, emphasizing that site-specific information constitutes the base of sound conservation management. The conservation status of Lyle's flying fox as Vulnerable (Bumrungsri et al. 2008), threats from hunting, and the loss of natural habitats in the study area highlight the need for continuous monitoring of the colonies at WL and WP to observe population trends, and emphasize the necessity of implementing an effective hunting ban. To alleviate conflicts with humans, we recommend future research on food preferences of Lyle's flying fox, and on the dependence of food plants on seed dispersal or pollination by bats. At the same time, managers should strive to retain native food plants and natural vegetation in the agricultural landscape of the study area to reduce consumption of and dependence on orchard fruits. If compatible with human land use, we anticipate that the bats would plant their own resources through seed dispersal, facilitating rejuvenation of natural vegetation in the longer term. Remaining patches of mangroves should be strictly protected from agricultural encroachment, preserving important foraging and roosting habitats of Lyle's flying fox. Enhancement of mangrove habitats in the study area would additionally benefit other wildlife and shoreline protection to prevent flooding. The bats at the temple colonies are used to and tolerate humans, and safety at these roosting sites as well as roosting trees should be continually maintained. We further recommend the installation of information plates at the temples that highlight the ecological role of Lyle's flying foxes as nocturnal gardeners while at the same time raising awareness of the risks associated with hunting and consumption of flying foxes for disease transmission, particularly for Nipah virus. Finally, information campaigns targeting local people should convey the message of crucial ecosystem services provided by the bats, their contribution to human well-being, and thus improve the public perception of flying foxes while minimizing humanwildlife conflicts.

\section{ACKNOWLEDGMENTS}

This study was jointly initiated and funded by the Max Planck Institute for Ornithology (MPIO), the Thailand Research Fund (RDG5420089) and The Food and Agriculture Organization of the United Nations (FAO). FAO was partly supported for this work by the Australian Department of Agriculture, Fisheries and Forestry (DAFF). Logistical support was provided by L. McCrickard, former FAO officer. K. Bunchornratana from Kasetsart University, Bangkok, assisted with field work. We would like to thank all resident people in the study area that accepted our research on their properties and shared their perception of flying foxes with us. The views expressed in this information product are those of the author(s) and do not necessarily reflect the views or policies of FAO.

\section{LITERATURE CITED}

Aldridge, H. D. J. N., and R. M. Brigham. 1988. Load carrying and maneuverability in an insectivorous bat: a test of the 5\% "rule" of radio telemetry. Journal of Mammalogy 69:379 382.

Banack, S. A. 1998. Diet selection and resource use by flying foxes (genus Pteropus). Ecology 79:1949 1967.

Banack, S. A., and G. S. Grant. 2002. Spatial and temporal movement patterns of the flying fox, Pteropus tonganus, in American Samoa. Journal of Wildlife Management 66:1154 1163.

Barbier, E. B. 2003. Habitat fishery linkages and mangrove loss in Thailand. Contemporary Economic Policy 21:59 77.

Benjawan, C., P. Chutichudat, K. Boontiang, and T. Chanaboon. 2006. Effect of chemical Paclobutrazol on fruit development, quality and fruit yield of Kaew mango (Mangifera indica L.) in Northeast Thailand. Pakistan Journal of Biological Sciences 9:717 722.

Breed, A. C., H. E. Field, C. S. Smith, J. Edmonston, and J. Meers. 2010. Bats without borders: long distance movements and implications for disease risk management. EcoHealth 7:204 212.

Bumrungsri, S., D. Lang, C. Harrower, E. Sripaoraya, K. Kitpipit, and P. A. Racey. 2013. The dawn bat, Eonycteris spelaea Dobson (Chiroptera: Pteropodidae) feeds mainly on pollen of economically important food plants in Thailand. Acta Chiropterologica 15:95 104.

Bumrungsri, S., A. Suyanto, and C. Francis. 2008. Pteropus lylei. IUCN Red List of Threatened Species. Version 2014.1.<www.iucnredlist.org>. Accessed 16 Apr 2014.

Corlett, R. T. 1998. Frugivory and seed dispersal by vertebrates in the Oriental (Indomalayan) Region. Biological Reviews of the Cambridge Philosophical Society 73:413 448.

Corlett, R. T. 2007. The impact of hunting on the mammalian fauna of tropical Asian forests. Biotropica 39:292 303.

Corlett, R. T. 2009. Seed dispersal distances and plant migration potential in tropical East Asia. Biotropica 41:592 598.

Daszak, P., C. Zambrana Torrelio, T. L. Bogich, M. Fernandez, J. H. Epstein, K. A. Murray, and H. Hamilton. 2012. Interdisciplinary approaches to understanding disease emergence: the past, present, and future drivers of Nipah virus emergence. Proceedings of the National Academy of Sciences 110:3681 3688.

de Jong, C., H. Field, A. Tagtag, T. Hughes, D. Dechmann, S. Jayme, J. H. Epstein, C. Smith, I. Santos, D. Catbagan, M. Lim, C. Benigno, P. Daszak, and S. Newman. 2013. Foraging behaviour and landscape utilisation by the endangered golden crowned flying fox Acerodon jubatus, The Philippines. PLoS ONE 8:e79665.

Eby, P. 1991. Seasonal movements of grey headed flying foxes, Pteropus poliocephalus (Chiroptera: Pteropodidae), from two maternity camps in northern New South Wales. Wildlife Research 18:547 559.

Epstein, J., H. Field, S. Luby, J. Pulliam, and P. Daszak. 2006. Nipah virus: impact, origins, and causes of emergence. Current Infectious Disease Reports 8:59 65.

Epstein, J. H., K. J. Olival, J. R. C. Pulliam, C. Smith, J. Westrum, T. Hughes, A. P. Dobson, A. Zubaid, S. A. Rahman, M. M. Basir, H. E. Field, and P. Daszak. 2009. Pteropus vampyrus, a hunted migratory species 
with a multinational home range and a need for regional management. Journal of Applied Ecology 46:991 1002.

Fujita, M. S., and M. D. Tuttle. 1991. Flying foxes (Chiroptera: Pteropodidae): threatened animals of key ecological and economic importance. Conservation Biology 5:455 463.

Gumal, M. T. 2004. Diurnal home range and roosting trees of a maternity colony of Pteropus vampyrus natunae (Chiroptera: Pteropodidae) in Sedilu, Sarawak. Journal of Tropical Ecology 20:247 258.

Hahn, M. B., J. H. Epstein, E. S. Gurley, M. S. Islam, S. P. Luby, P. Daszak, and J. A. Patz. 2014. Roosting behaviour and habitat selection of Pteropus giganteus reveal potential links to Nipah virus epidemiology. Journal of Applied Ecology 51:376 387.

Harrison, M. E., S. M. Cheyne, F. Darma, D. A. Ribowo, S. H. Limin, and M. J. Struebig. 2011. Hunting of flying foxes and perception of disease risk in Indonesian Borneo. Biological Conservation 144:2441 2449.

Hazarika, M. K., L. Samarakoon, K. Honda, J. Thanwa, T. Pongth anapanich, and K. Boonsong. 2000. Monitoring and impact assessment of shrimp farming in the East Coast of Thailand using remote sensing and GIS. International Archives of Photogrammetry and Remote Sensing 33, Part B 7:504 510.

Hengjan, Y. 2011. Seasonal variation in emergence and activity pattern at roosting site of Lyle's flying fox Pteropus lylei Andersen, 1908 at Wat Pho, Chachoengsao Province. Thesis, Chulalongkorn University, Bangkok, Thailand.

Hillman, R. A. 2005. Distribution of Lyle's flying fox (Pteropus lylei) camps in central Thailand. Natural History Bulletin of the Siam Society 53:142 144 .

Hodgkison, R., S. T. Balding, A. Zubaid, and T. H. Kunz. 2003. Fruit bats (Chiroptera: Pteropodidae) as seed dispersers and pollinators in a lowland Malaysian rain forest. Biotropica 35:491 502

Holland, R. A., M. Wikelski, F. Kummeth, and C. Bosque. 2009. The secret life of oilbirds: new insights into the movement ecology of a unique avian frugivore. PLoS ONE 4:e8264.

Kunz, T. H., E. B. de Torrez, D. Bauer, T. Lobova, and T. H. Fleming. 2011. Ecosystem services provided by bats. Annals of the New York Academy of Sciences 1223:1 38.

Luskin, M. S. 2010. Flying foxes prefer to forage in farmland in a tropical dry forest landscape mosaic in Fiji. Biotropica 42:246 250.

Mahmood ul Hassan, M., T. L. Gulraiz, S. A. Rana, and A. Javid. 2010. The diet of Indian flying foxes (Pteropus giganteus) in urban habitats of Pakistan. Acta Chiropterologica 12:341 347.

Markus, N., and J. K. Blackshaw. 2002. Behaviour of the black flying fox Pteropus alecto: 1 . An ethogram of behaviour, and preliminary characteri sation of mother infant interactions. Acta Chiropterologica 4:137 152.

McConkey, K. R., and D. R. Drake. 2006. Flying foxes cease to function as seed dispersers long before they become rare. Ecology 87:271 276.

McDonald Madden, E., E. S. G. Schreiber, D. M. Forsyth, D. Choquenot, and T. F. Clancy. 2005. Factors affecting grey headed flying fox (Pteropus poliocephalus: Pteropodidae) foraging in the Melbourne metropolitan area, Australia. Austral Ecology 30:600 608.

Mickleburgh, S. P., A. M. Hutson, and P. A. Racey. 1992. Old World fruit bats: an action plan for their conservation. International Union for Conservation of Nature and Natural Resources (IUCN), Gland, Switzerland.

Mickleburgh, S. P., K. Waylen, and P. A. Racey. 2009. Bats as bushmeat: a global review. Oryx 43:217 234.

Mohd Azlan, J., A. Zubaid, and T. H. Kunz. 2001. Distribution, relative abundance, and conservation status of the large flying fox, Pteropus vampyrus, in peninsular Malaysia: a preliminary assessment. Acta Chiropterologica 3:149 162.

Muscarella, R., and T. H. Fleming. 2007. The role of frugivorous bats in tropical forest succession. Biological Reviews 82:573 590.

Nartvaranant, P., S. Subhadrabandhu, and P. Tongumpai. 2000. Practical aspect in producing off season mango in Thailand. Acta Horticulturae 509:661 668

Nelson, J. E. 1965. Behaviour of Australian pteropodidae (Megachiroptera). Animal Behaviour 13:544 557.

Nelson, S. L., M. A. Miller, E. J. Heske, and G. C. Fahey Jr. $2000 a$ Nutritional consequences of a change in diet from native to agricultural fruits for the Samoan fruit bat. Ecography 23:393 401.

Nelson, S. L., M. A. Miller, E. J. Heske, and G. C. Fahey Jr. $2000 b$ Nutritional quality of leaves and unripe fruit consumed as famine foods by the flying foxes of Samoa. Pacific Science 54:301 311.
Ochoa Acuna, H., and T. H. Kunz. 1999. Thermoregulatory behavior in the small island flying fox, Pteropus hypomelanus (Chiroptera: Pteropodidae). Journal of Thermal Biology 24:15 20.

Olson, J. G., C. Rupprecht, P. E. Rollin, U. S. An, M. Niezgoda, T. Clemins, J. Walston, and T. G. Ksiazek. 2002. Antibodies to Nipah like virus in bats (Pteropus lylei), Cambodia. Emerging Infectious Diseases 8:987 988.

O'Mara, M. T., M. Wikelski, and D. K. N. Dechmann. 2014. 50 years of bat tracking: device attachment and future directions. Methods in Ecology and Evolution 5:311 319.

Pierson, E. D., and W. E. Rainey. 1992. The biology of flying foxes of the genus Pteropus: a review. Pages 117 in D. E. Wilson, and G. L. Graham, editors. Pacific island flying foxes: proceedings of an international conservation conference. U.S. Fish and Wildlife Service Biological Report 90(23), Washington, D.C., USA.

Prasad, E. R., P. Dileep, M. P. Aryasree, K. Anjana, and P. Sunojkumar. 2014. Foraging behaviour of Indian flying fox $P$. giganteus in Kerala. Annals of Plant Sciences 3:883 887.

Reynes, J. M., D. Counor, S. Ong, C. Faure, V. Seng, S. Molia, J. Walston, M. C. Georges Courbot, V. Deubel, and J. L. Sarthou. 2005. Nipah virus in Lyle's flying foxes, Cambodia. Emerging Infectious Diseases 11:1042 1047.

Roberts, B. J., C. P. Catterall, P. Eby, and J. Kanowski. 2012. Long distance and frequent movements of the flying fox Pteropus poliocephalus: implications for management. PLoS ONE 7:e42532.

Scheffers, B. R., R. T. Corlett, A. Diesmos, and W. F. Laurance. 2012. Local demand drives a bushmeat industry in a Philippine forest preserve. Tropical Conservation Science 5:133 141.

Shanahan, M., S. So, S. G. Compton, and R. Corlett. 2001. Fig eating by vertebrate frugivores: a global review. Biological Reviews 76: 529572.

Shilton, L. A., J. D. Altringham, S. G. Compton, and R. J. Whittaker. 1999. Old World fruit bats can be long distance seed dispersers through extended retention of viable seeds in the gut. Proceedings of the Royal Society of London Series B Biological Sciences 226:219 223.

Sikes, R. S., W. L. Gannon. and theAnimal Care and Use Committee of the American Society of Mammalogists. 2011. Guidelines of the American Society of Mammalogists for the use of wild mammals in research. Journal of Mammalogy 92:235 253.

Sodhi, N. S., L. P. Koh, B. W. Brook, and P. K. L. Ng. 2004. Southeast Asian biodiversity: an impending disaster. Trends in Ecology \& Evolution 19:654 660 .

Sritongchuay, T., G. A. Gale, A. Stewart, T. Kerdkaew, and S. Bumrungsri. 2014. Seed rain in abandoned clearings in a lowland evergreen rain forest in Southern Thailand. Tropical Conservation Science 7:572 585.

Start, A. N., and A. G. Marshall. 1976. Nectarivorous bats as pollinators of trees in West Malaysia. Pages 141149 in J. Burley, and B. T. Syles, editors. Tropical trees: variation, breeding and conservation. Academic Press, London, United Kingdom.

Stier, S. C., and T. L. Mildenstein. 2005. Dietary habitat of the world's largest bats: the Philippine flying foxes, Acerodon jubatus and Pteropus vampyrus lanensis. Journal of Mammalogy 86:719 728.

Sudhakaran, M. R., and P. S. Doss. 2012. Food and foraging preferences of three pteropodid bats in southern India. Journal of Threatened Taxa 4:2295 2303.

Tidemann, C. R., M. J. Vardon, R. A. Loughland, and P. J. Brocklehurst. 1999. Dry season camps of flying foxes (Pteropus spp.) in Kakadu World Heritage Area, north Australia. Journal of Zoology 247:155 163.

van der Pijl, L. 1982. Principles of dispersal in higher plants. Springer Verlag, Berlin, Germany.

Vendan, S. E., and B. Kaleeswaran. 2011. Plant dispersal by Indian flying fox Pteropus giganteus in Madurai region, India. Elixier Bio Diversity 30:1810 1813

von Helversen, O., and Y. Winter. 2003. Glossophagine bats and their flowers: costs and benefits for plants and pollinators. Pages 346397 in T. H. Kunz, and M. B. Fenton, editors. Bat Ecology. The University of Chicago Press, Chicago, Illinois, USA.

Wacharapluesadee, S., K. Boongird, S. Wanghongsa, P. Phumesin, and T. Hemachudha. 2006. Drinking bat blood may be hazardous to your health. Clinical Infectious Diseases 43:269.

Wacharapluesadee, S., K. Boongird, S. Wanghongsa, N. Ratanasetyuth, P. Supavonwong, D. Saengsen, G. N. Gongal, and T. Hemachudha. 2010. A longitudinal study of the prevalence of Nipah virus in Pteropus lyle $i$ bats in Thailand: evidence for seasonal preference in disease transmission. Vector Borne and Zoonotic Diseases 10:183 190. 
Wacharapluesadee, S., B. Lumlertdacha, K. Boongird, S. Wanghongsa, L. Chanhome, P. Rollin, P. Stockton, C. E. Rupprecht, T. G. Ksiazek, and T. Hemachudha. 2005. Bat Nipah virus, Thailand. Emerging Infectious Diseases 11:1949 1951.

Waggener, T. R. 2001. Logging bans in Asia and the Pacific: an overview. Pages 142 in P. B. Durst, T. R. Waggener, T. Enters, and T. L. Cheng, editors. Forests out of bounds: impacts and effectiveness of logging bans in natural forests in Asia Pacific. Food and Agriculture Organization of the United Nations (FAO), Regional Office for Asia and the Pacific, Bangkok, Thailand.

Watzke, S. 2006. Ressourcennutzung und Paarungssystem der nektarivoren Flughundart Macroglossus minimus (Pteropodidae: Macroglossinae) in West Malaysia. Dissertation, Ludwig Maximilians Universitat, Munchen, Germany. [In German.]

Wikelski, M., and R. Kays. 2010. Movebank: archive, analysis and sharing of animal movement data. $<$ http://www.movebank.org $>$. Accessed $27 \mathrm{Feb} 2014$.
Wolfe, N. D., C. P. Dunavan, and J. Diamond. 2007. Origins of major human infectious diseases. Nature 447:279 283.

Wood, J. L., M. Leach, L. Waldman, H. Macgregor, A. R. Fooks, K. E. Jones, O. Restif, D. Dechmann, D. T. Hayman, K. S. Baker, A. J. Peel, A. O. Kamins, J. Fahr, Y. Ntiamoa Baidu, R. Suu Ire, R. F. Breiman, J. H. Epstein, H. E. Field, and A. A. Cunningham. 2012. A framework for the study of zoonotic disease emergence and its drivers: spillover of bat pathogens as a case study. Philosophical Transactions of the Royal Society B Biological Sciences 367:2881 2892. 